\title{
Play in kittens (Felis domesticus) and its association with cohesion and aggression
}

\author{
DIANA L. MENDOZA and J. MARTIN RAMIREZ \\ Seville University, Seville, Spain
}

\begin{abstract}
The behavior of 7 cats was observed from birth to the age of 25 weeks. This longitudinal study indicates that the onset of two types of play coincides with the onset of different types of social interactions. For social play the peak of occurrence was during Weeks 9-14, whereas for nonsocial play it was during Weeks 18-21. In addition, a predominance of cohesive behaviors was observed during the earlier period (Weeks 9-14) and of aggressive behaviors during the later period (Weeks 18-21). These results highlight the fact that the timing of stages in cats' development and suggest that there is a reorganization of play activity of kittens around the 4th week of their lives.
\end{abstract}

The domestic cat, like many other felids, tends to have a solitary existence. In its natural setting, the cat has few social interactions. During its adult life, for instance, a cat does not necessarily come in close contact with its neighbors, even though they may share a pathway, for they do not use it simultaneously (Leyhausen, 1979). During its life, however, there are two periods when a cat experiences more frequent social interactions; one is during the breeding season, and the other is during early age. The description of what happens as the young cat grows older is interesting, not only for the study of socialization, but also for proper understanding of behavioral developmental processes. There are several ways in which young cats socially interact: by playing, by grooming, and by social investigation.

Play is an interesting example of behavior in development: it is a juvenile activity characteristic of animals that are growing, rather than of those that are already adult. Although play seems to occur especially at this early stage in life, it is widely recognized as an important part in the development of adult behavior. In recent years an increasing number of attempts have been made to understand the nature and function of play in cats. Speculations about the function of play have been wide-ranging and imaginative. Although there are some researchers who dismiss play as an invalid or scientifically useless categorization (Berlyne, 1969; Welker, 1971), most agree on the importance of play in cats' future development. Theories abound with respect to the importance of play for a cat that is learning

This work was made possible by a grant from the Alexander von Humboldt Foundation to the second author. The manuscript was written while both authors were visiting scholars at Stanford University, holding the US-Spain Joint Committee for Cultural and Educational Affairs fellowships. We acknowledge our debt to C. Mosher, S. Levine, and K. H. Pribram for their critical comments as well as to our students, C. Salas, A. del Toro, J. Rodriguez, and J. Valls, for their assistance.

The authors' mailing address is: Department of Psychobiology, Seville University, Apartado 3128, Seville 41080, Spain. about itself and its environment (Loizos, 1967; MullerSchwarze, 1971). Baldwin and Baldwin (1977) listed 30 functions of play, which more recently have been reduced by Bekoff and Byers (1981) to three: motor training, socialization, and cognitive training. Most modern theories claim that play may not be necessary for the development of normal behavior, but it might nonetheless improve those skills that are already developing. Currently, however, assumptions as to the functions of play remain speculative, still hampered by incomplete empirical evidence. Recently the emphasis has shifted toward experimental studies, based on quantitative data and more detailed descriptions and coherent explanations of what actually happens during the development of play in cats, because this knowledge is important in order to explain the content and function of play. There is still little experimental support for any of the functional interpretations.

Even though there is great confusion over the meaning of the term play (Hinde, 1970, 1974; Martin \& Caro, 1985), it is possible to study play empirically without a satisfactory definition. Observers certainly have a strong subjective recognition of an animal at play; the distinguishing feature seems to be, in addition to a series of constituent motor acts and contextual clues, the subjective sense that play lacks any obvious purpose or immediate benefit (Hinde, 1970; Smith, 1982). Play, therefore, can be descriptively defined as "all locomotor activity that appears to have no obvious immediate benefits for the player"' (a modified version of definitions by Bekoff and Byers [1981] and Martin and Caro [1985]). Several types of play activity are easily recognized in the domestic cat: social play, nonsocial play, and predatory play (see the descriptions in Methods).

Because the accepted characteristics of play imply sufficient knowledge to allow its use as a dependent variable and because ethological methods make it possible to measure relevant variables without understanding their interactions, an ethological approach to play offers excellent 
opportunities for the study of conflict and compromise in relationships (West, 1974). The purposes of this study were to examine the timing of the onset, peak, and decline of social and nonsocial play activities during the first 25 weeks of a cat's life (most of the previously mentioned studies have limited their reports to the first 12 weeks of kittens' lives); to describe some developmental changes and preferences with age; and to determine if there is any significant association between play and two important facets of a cat's social interaction: aggression and cohesion.

\section{METHOD}

\section{Subjects}

The subjects were 7 male kittens (Felis domesticus) from two litters. The young were kept with their mothers for the duration of the experiment; they were reared in a $6 \times 4 \mathrm{~m}$ room that received natural lighting through windows. The cats were fed once a day; their diet included milk, raw meat, and Purina Cat Chow. Water was always available.

\section{Procedure}

Observations were evenly distributed between 9 a.m. and 5 p.m. Each subject was observed in random order for 181 -min observation periods each day; for the whole colony, a total of $252 \mathrm{~h}$ was recorded in writing. In addition to written records, a total of $800 \mathrm{~min}$ of videotape was recorded. The behaviors selected were coded recording the actor and the target of each interaction, according to a system reported elsewhere (Mendoza, 1982). A matrix-completion sampling method (Ramirez \& Mendoza, 1984) was used. The behaviors studied in this species consisted of 35 items coded in a checklist. For the purpose of the present study, the following items were selected: 5 items related to play (pounces, chases, horizontal leaps, belly-up patterns, and stand-up patterns); 4 items related to cohesion (approach, physical contact, interindividual closeness [ 2 subjects staying together at a distance closer than $30 \mathrm{~cm}$ for more than $30 \mathrm{sec}$, and nose-nose contact), and 2 items related to aggression (arching the back and biting).

Depending on the target of the interaction, the following kinds of play were cataloged: (1) social play, directed at conspecifics and described as a "stereotyped form of physical interaction between individuals" (Ewer, 1968); (2) predatory play, directed toward living or dead prey; and (3) nonsocial play, directed either toward inanimate objects and described as "manipulation of an object by tossing, grasping, scooping, poking, batting, and/or mouthing often preceded by pouncing or leaping on the object and often followed by the same 2-behaviors"' (West, 1977), or toward itself in apparently spontaneous movements that carry the individual about its environment (Martin \& Caro, 1985).
Data collected from each kitten were combined with those of its siblings, and the percentage of time the kittens spent in each type of behavior during observation periods was averaged for each week. The statistical analysis was carried out on data lumped together from the 10-14 week-old period and that from the 18-21 week-old period. The chi-square test was applied to determine significant differences in the percentage of occurrences between the early and late ptriods.

\section{RESULTS}

The ontogenetic developmental trend of social play was different from that found for nonsocial play (see Figure 1). Social play typically involved 2 kittens, but often more than 2 were engaged. Kittens began to approach, paw, and hold each other at 2-3 weeks. Clearly defined play appeared at 3 weeks of age, with patterns such as bellyup and stand-up. The onset of other play patterns was at different ages, the latest being the horizontal leap, at about Week 6 or 7 of play activity. After Week 6, play sharply increased, reaching a peak from about Week 9 to Week 14. After Week 14, play dramatically declined until approximately Week 19 . After this, play occurred very infrequently, less than once per day. Although kittens were becoming interested in objects by Week 4 or 5 , object play did not clearly increase until between Weeks 9 and 12, reaching a peak at Week 18, with a plateau up to Week 21; after that, a gradual decline was observed. Although some adult cats continued to play vigorously with objects by themselves, few played with their peers; some mothers, however, played with their offspring.

These trends of play show a marked correlation with the trends of other facets of cats' behavior: cohesive patterns were closely associated with each other and were significantly higher at the peak of social play than at the peak of nonsocial play: approach $(79 \%$ vs. $36 \%)$, nose-nose contact (58\% vs. $20 \%$ ), interindividual closeness ( $44 \%$ vs. $12 \%$ ), and physical contact ( $36 \%$ vs. $14 \%$ ). During nonsocial play, aggressive behavioral patterns among kittens were significantly higher than during social play: arching ( $72 \%$ vs. $24 \%)$ and biting $(61 \%$ vs. $22 \%$ ) (see Figure 2). These latter patterns become dis-

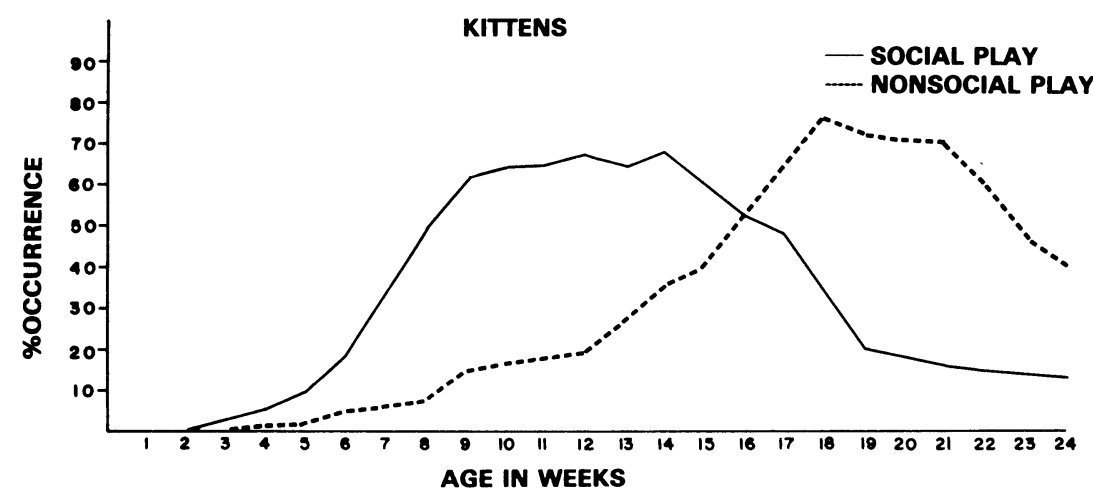

Figure 1. Trends of the occurrence of social and nonsocial play in kittens from birth to 24th week of age. 


\section{COHESIVE AND AGRESSIVE BEHAVIOR DURING THE PEAK OF SOCIAL AND MON-SOCIAL PLAY}

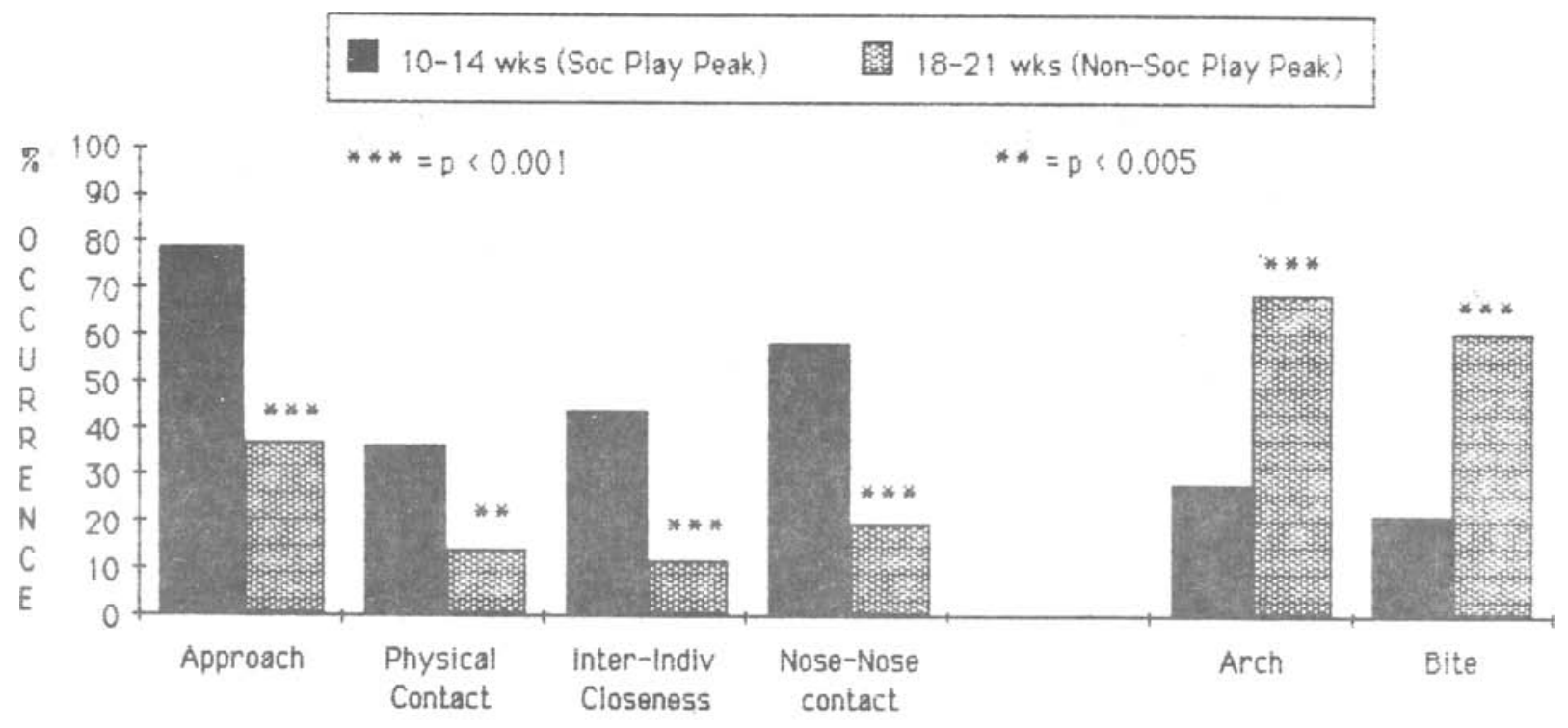

COHESION

AGRESSION

Figure 2. Occurrence (\%) of several cohesive and aggressive behaviors in cats during the peaks of social and nonsocial play.

sociated from cohesive patterns during development; the arched-back posture, for instance, very seldom occurred during social play.

\section{DISCUSSION}

The present longitudinal study indicates the existence of different kinds of play in cats, with different developmental trends. Each kind of play emerges at a certain stage in the kitten's growth: a kitten's attention is first focused on conspecifics (approaching, pawing, and holding each other) and is then switched to inanimate objects and prey (Caro, 1981). The fact that the peaks of social and nonsocial play are at different times is evidence of a marked discontinuity in development (Bateson, 1981), suggesting that the two types of play are rather independent systems. This reorganization in play activity (i.e., the decrease in preference for social contact and the increase in exploration of inanimate environment) that happened around the 4th month of age probably represents a marked restructuring of cats' behavior arising from internal and external variables, such as biological maturation and changes in the environment.

To explain cats' internal maturation, researchers have proposed plausible functional links between this behavioral reorganization and weaning (Bateson \& Young, 1981) or physical exercise (West, 1974). Those explanations, however, are not entirely satisfactory. In our captivity setting, the age of weaning was later than the $\mathbf{5 0}$ days reported for feral cats, but the timing of the developmental changes in play did not seem to shift. Also, although play seems to help in developing physical ability, there is a lack of correlation between the play trends (that sharply increase) and the motor activity score (that gradually increases). Since play provides ample opportunity for physical exercise, it might also be related to kittens' needs.

Changes in the environment might also have an influence on play behavior. From birth to the 4th month, kittens have a high incidence of sibling contact, because they confine themselves to a small area, because of their inability to travel, and because of the need to be close to their mother for nourishment. Social play might then be expected when siblings are readily available. About the 4th month of age, important behavioral changes occur: kittens move less, they sit and sleep more, they tend to disperse away from their littermates, and they devote more time to exploring their environmental world. (The 4th month is the time when, in feral cats, mothers leave their children and, consequently, kittens have to find all their own food.) During this period of increased opportunities for exploration, more object (nonsocial) play was observed, as expected.

This behavioral reorganization, rather than being due to a real dispersal of the young (West, 1974) and fewer opportunities for social contact (Bateson \& Young, 1981), seems to be related to changing preferences (tendency to decrease social contacts and to increase exploration and dispersal), as suggested by the present results: cats living socially in the laboratory with siblings until 6 months showed changes similar to those in cats we observed in this study (see also Koepke \& Pribram, 1971).

Most patterns recorded in this study correspond with those previously reported in the literature; curve forms and timing of onset of the different behaviors were also similar. Several discrepancies related to the timing of decline were observed, however: our six-month observations, obviously, showed changes and trends not found in other reports, which were limited to 12 weeks. Also, there was an intriguing difference between our findings and those of Caro (1981), who reported that the rate of arching sharply increased for only Weeks 6 and 7, and then declined for the rest of the 12 weeks of observation to the previous low level. Although the present data also show an increase in Week 6, arching did not decline later; on the contrary, it remained at the same level until Week 16, when it again increased, reaching its highest plateau during the last 4 weeks (20-24) of our study. Nevertheless, the timing and magnitude of changes in different behavioral measures should not be treated as absolute, because they might be influenced by experimental designs and environmental conditions; for example, Koepke and Pribram (1971) observed that the timing of the peak of play was dramatically influenced by the way the kittens had been fed, and Bateson and Young (1981) also reported influence of the separation of the mother on the kittens' play behavior.

A third kind of play behavior, not treated in the present study, is predatory play. It first appears during Week 4 of life (Caro, 1981) and is still 
still present in some adult cats: one sixth of mousekillers showed prekilling play with the mouse lasting up to $12 \mathrm{~min}$ (J. M. Ramirez, unpublished observations). According to Biben (1979), the amount of predatory play in adults depends upon both hunger and prey size.

Finally, these results showed that social play and cohesive patterns, which strengthen the bond among kittens, develop at the same time and that nonsocial play and disruptive patterns, which lead to disperse individuals, also develop at about the same time.

\section{REFERENCES}

BALDWIN, J. D., \& BALDWIN, J. I. (1977). The role of learning phenomena in the ontogeny of exploration and play. In S. ChevalierSkolnikoff \& F. E. Poirier (Eds.), Primate biosocial development (pp. 343-406). New York: Garland.

Bateson, P. (1981). Discontinuities in development and changes in the organization of play in cats. In K. Immelmann, G. W. Barlow, L. Petrinovich, \& M. Main (Eds.), Behavioral development. The Bielefeld Interdisciplinary Project (pp. 296-337). Cambridge: Cambridge University Press.

Bateson, P., \& Young, M. (1981). Separation from the mother and the development of play in cats. Animal Behavior, 29, 173-180.

BeKoFf, M., \& BYers, J. A. (1981). A critical analysis of the ontogeny and phylogeny of mammalian social and locomotor play: An ethological hornet's nest. In $\mathbf{K}$. Immelmann, G. W. Barlow, L. Peuinovich, \& M. Main (Eds.), Behavioral development. The Bielefeld Interdisciplinary Project. Cambridge: Cambridge University Press.

BerLyNe, D. E. (1969). Curiosity and exploration. Science, 153, 25-33.

BiBEN, M. (1979). Predation and predatory play behavior of domestic cats. Animal Behaviour, 27, 81-94.

CARo, T. M. (1981). Predatory behavior and social play in kittens. Behavior, 76, 1-24.

Ewer, R. (1968). Ethology of mammals. New York: Plenum Press.

Guyot, G. W., Bennett, T. L., \& Cross, H. A. (1980). The effects of social isolation on the behavior of juvenile domestic CATS. Developmental Psychobiology, 13, 317-319.
Hinde, R. A. (1970). Animal behaviour (2nd ed.). New York: McGraw-Hill.

HINDE, R. A. (1974). Biological bases of human social behaviour. New York: McGraw-Hill.

KoepKe, J. E., \& Pribram, K. H. (1971). Effect of milk on the maintenance of sucking behavior in kittens from birth to six months. Journal of Comparative \& Physiological Psychology, 75, 363-377.

LEYHAUSEN, P. (1979). Cat behavior: The predatory and social behavior of domestic and wild cats. New York: Garland STPM Press.

Lorzos, C. (1967). Play behaviour in higher primates: A review. In D. Morris (Ed.), Primate ethology (pp. 176-181). London: Weidenfeld and Nicolson.

Martin, P., \& Caro, T. M. (1985). On the functions of play and its role in behavioral development. Advances in the Study of Behavior, 15, 59-103.

MendozA, D. L. (1982). Organizacion social de los monos Barizo (Saimiri sciureus). Unpublished doctoral dissertation, Universidad Complutense de Madrid.

MUlleR-SCHWARZE, D. (1971). Ludic behavior in young mammals. In M. B. Sterman, D. J. McGinty, \& A. M. Adinolfi (Eds.), Brain development and behavior (pp. 229-249). New York: Academic Press.

RAmirez, J. M., \&endozA, D. L. (1984). Gender differences in social interaction of children: A naturalistic approach. Bulletin of the Psychonomic Society, 22, 553-556.

SmITH, P. K: (1982). Does play matter? Functional and evolutionary aspects of animal and human play. Behavioral \& Brain Sciences, 5 , 139-184.

WELKER, W. (1971). Ontogeny of play and exploratory behaviors: A definition of problems and search for new conceptual solutions in $\mathrm{H}$. Moltz (Ed.), The ontogeny of vertebrate behavior (pp. 171-228). New York: Academic Press.

West, M. (1974). Social play in the domestic cat. American Zoologist, 14, 427-436.

West, M. (1977). Exploration and play with objects in domestic kittens. Developmental Psychobiology, 10, 53-57.

(Manuscript received for publication August 18, 1986.) 